\title{
Challenges Experienced of Nurses Caring for Syrian Refugee Children
}

\author{
Suzan Tek' ${ }^{(D,}$, Hülya Karataș² (D), Firdevs Erdemir ${ }^{3}$ (D), Candan Öztürk ${ }^{4}$ (i) \\ 'Department of Child Health Nursing, Yozgat Bozok University Faculty of Nursing, Yozgat, Turkey \\ 2Department of Nursing, Harran University School of Medicine, Sanlıurfa, Turkey \\ ${ }^{3}$ Department of Child Health Nursing, Near East University Faculty of Nursing, Mersin, Turkey \\ ${ }_{4}^{4}$ Department of Child Health Nursing, Near East University Faculty of Nursing, Mersin, Turkey
}

ORCID iDs of the authors: S.T. 0000-0002-4969-9348; H.K. 0000-000I-63I2-5028; F.E. 0000-0002-I335-555I; C.0̈. 0000-0002-0909-50I3.

Cite this article as: Tek S, Karataș H, Erdemir F, Öztürk C. Challenges Experienced of Nurses Caring for Syrian Refugee Children. Cyprus J Med Sci 202I; 6(I): 74-9.

\section{BACKGROUND/AIMS}

This study was carried out to determine the challenges experienced by the nurses providing care to Syrian pediatric patients.

\section{MATERIAL and METHODS}

This study was conducted on 13 nurses working in newborn service, preschooler and school-age children service, pediatric service, and newborn intensive care service of a hospital that provides care for Syrian pediatric patients in a city on the Syrian border of Turkey. Data were collected using a semi structured interview form and a focus group method. Themes were determined by content analysis.

\section{RESULTS}

Themes that were determined in the study included the challenges arising from communication, life circumstances, cultural differences, and compassion fatigue, and recommendations for overcoming these challenges were made.

\section{CONCLUSION}

The results of this study can be a guide for making the necessary arrangements so that nurses can provide more effective care while working with patients who have similar characteristics, and these results can be a guide for similar problems that may be experienced in different countries.

Keywords: Child, nurses, refugees, focus groups, interview

\section{INTRODUCTION}

The internal conflict in the Syrian Arab Republic began in the early spring of 2011 and has forced millions of people to seek asylum in countries in the region. As of September 2018, over 5.6 million people have fled the country since the beginning of the internal conflict, seeking safety in Jordan, Lebanon, Turkey, and beyond (I). Turkey, the country that hosts more Syrians than any other country, shelters 3.5 million Syrian refugees, of whom, 1.5 million are children (2). The issue of meeting the healthcare needs of children and families is rapidly becoming more significant (3). The highest number of applications made for receiving healthcare services was for the children of Syrian refugees (4). Studies suggest that refugees experience mental problems along with physical ones resulting from their displacement $(3,5,6)$. Therefore, it is necessary to provide comprehensive healthcare services to this group. There are studies conducted to determine the problems regarding Syrian patients' needs and difficulties, but the number of studies specifying the difficulties that nurses face while providing care to this group is still limited (7-10). Whereas Syrian patients experienced difficulties in communicating, in meeting their personal needs, and in correctly following treatment instructions, nurses experienced difficulty in communicating with Syrian refugees and their families in the clinic. The studies in this field suggest that describing the patients' opinions can act as a guide for planning nursing care; however, these studies also imply that description of nursing care should be considered for patients' medical results. This study aims to determine the challenges nurses face while providing care to Syrian pediatric patients and their families. The results of this study are thought to have positive effects on healthcare services provided for children who are refugees and their families. 


\section{MATERIALS and METHODS}

This study was conducted with 13 nurses working in a children's hospital that provides care for Syrian children and their parents in Șanlıurfa province, the province with the second largest population of Syrian refugees in Turkey (II). The inclusion criterion was working with Syrian pediatric patients for at least 6 months.

The data were collected using a semistructured interview form and a focus group method. Information about nurses' demographical characteristics was obtained through a sociodemographic form. There were a total of 6 open-ended questions focused on the challenges the nurses experienced when providing care to Syrian pediatric patients. Before initiating the study, a pilot study was conducted with 5 nurses to determine whether or not the questions were suitable. The interview was conducted I time by 2 researchers. One researcher conducted the interview, whereas the other observed. The interview was conducted in a hospital seminar room for I h, $18 \mathrm{~min}$, and $33 \mathrm{~s}$. The interview was conducted until thematic saturation was reached. The interview was recorded using an audio system.

The following questions were asked:

I. How did you feel when you first provided care to a Syrian pediatric patient? Can you share your feelings and experiences with us?

2. How was the experience of providing care service to pediatric patients and their parents who migrated from Syria? What are your personal feelings toward this experience?

3. What sort of challenges do the nurses experience when they provide care to pediatric patients who migrated from Syria?

4. In your opinion, how should nurses providing care to Syrian children be supported?

5. What should be done to improve the nursing care for Syrian children?

6. Is there anything you want to add?

Nurses' sociodemographic characteristics were analyzed using descriptive statistics. In this study, a total of 13 nurses were interviewed using the focus group method. A total of 13 pages of documentation were obtained after completing the interviews. The data were assessed using content analysis, and the main themes and subthemes were determined after the researchers independently compared the coding processes $(12,13)$.

\section{Main Points:}

- The experienced by nurses' difficulties were identified as communication, cultural difference, living conditions and compassion fatigue.

- Suggestions for reducing these challenges included improving the number and quality of interpreters; enhancing cultural competence through initiatives, such as planning trainings to cope with cultural differences; and providing support for dealing with compassion fatigue.

- This is the first study with nurses working with children, the group most affected by the war. The results of this study can be used as a guide for similar problems that may occur in different countries.
Written approval for the study was obtained from the institutions (14.01.2015). The participants signed an informed approval form.

\section{RESULTS}

Demographic characteristics and unit and duration of working with Syrian pediatric patients are presented in Table I. The mean age of nurses was $31.4 \pm 6.80$ (24-46) years; $92.3 \%$ of the nurses were female. Although the average work duration of the nurses was $8.30 \pm 5.31(1-17)$ years, they have been working in the pediatric unit for an average of $3.69 \pm 2.05$ (1-9) years. The main theme and subthemes were set in the study (Table 2 ). The five main themes and subthemes are described in the following sections:

\section{Theme l: Challenges Related to Communication}

The language barriers and interpreters' qualitative and quantitative insufficiencies are included in the subthemes of this theme.

Subtheme I: Language Barrier. A nurse aged 30 years who has 6 years of experience stated the challenges about language as follows: "We have problems in communicating with the children. We usually play games, talk and use words on their level to communicate so that we can prepare them for the process, but we cannot use these techniques with Syrian children so we cannot prepare them for the process."

Subtheme II: Interpreters' Qualitative Insufficiency. One of the subthemes of communication challenges is interpreters' qualitative insufficiency. Nurses stated that they were unsure whether the things they said were communicated correctly because the interpreters' qualitative skills were insufficient. A nurse aged 46 years stated the following:

We said something negative about a child's condition but mother's facial expression was happy. .... we asked the interpreter to tell the mother that the child's condition was serious and an operation was necessary, but the mother's facial expression did not indicate any concerns-so we understood that our statement was misinterpreted.

Subtheme III: Interpreters' Quantitative Insufficiency. In addition to qualitative insufficiencies in communication, the insufficient number of interpreters in the hospital was another subtheme. A nurse working with Syrian patients for 4 years stated as follows: "We cannot always find an interpreter: there is only one interpreter in the hospital who cannot keep up with the demands."

\section{Theme II: Challenges Related to Living Conditions}

Nurses stated the challenges arising from living conditions. Along with patients' financial problems, the bureaucratic process negatively affected the treatment and care.

Subtheme I: Financial. The nurse working in the intensive care unit described the effect of financial problems on treatment as follows: "You need diapers or creams for baby care which are something health care personnel occasionally buy with her/ his own money. Although the government provides diapers and other needs, it is not enough. You tell the mother to buy these things but she cannot afford." 


\begin{tabular}{|c|c|c|c|c|c|c|}
\hline Code & Age & Gender & Graduation & Work year & Clinic & Caregiving years \\
\hline I & 46 & Female & Undergraduate & 17 & Newborn & 4 \\
\hline 3 & 38 & Female & Undergraduate & 15.5 & 4.breastfed & 4 \\
\hline 4 & 25 & Female & Undergraduate & 3.5 & Newborn & 3.5 \\
\hline 6 & 32 & Female & Undergraduate & 8 & $\mathrm{NICU}$ & 1 \\
\hline 7 & 25 & Female & Undergraduate & 1 & I.breastfed & 1 \\
\hline 8 & 28 & Male & Undergraduate & 5 & 6.breastfed & 1 \\
\hline 9 & 28 & Female & Undergraduate & 5 & 5.breastfed & 4 \\
\hline 13 & 28 & Female & Undergraduate & 4 & 3. child & 4 \\
\hline
\end{tabular}

\section{TABLE 2. Themes for the nurse's challenges}

\begin{tabular}{|c|c|}
\hline Themes & \\
\hline \multirow[t]{3}{*}{ Theme I. Communication } & Language Barrier \\
\hline & Qualitative insufficiency of interpreter \\
\hline & Quantitative insufficiency of interpreter \\
\hline \multirow[t]{2}{*}{$\begin{array}{l}\text { Theme II. Migrants' } \\
\text { living conditions }\end{array}$} & Financial \\
\hline & Bureaucratic \\
\hline \multirow[t]{2}{*}{ Theme III. Cultural differences } & Nutrition \\
\hline & Hygiene \\
\hline \multirow[t]{3}{*}{$\begin{array}{l}\text { Theme IV. Sense of providing } \\
\text { effective care }\end{array}$} & Sadness \\
\hline & Empathy \\
\hline & Feeling of insufficient \\
\hline \multirow[t]{4}{*}{ Theme $\vee$. Recommendations } & Communication \\
\hline & Cultural differences \\
\hline & Living conditions \\
\hline & Workload \\
\hline
\end{tabular}

Subtheme II: Bureaucracy. Failure to reach the family because of bureaucratic procedures can delay the treatment. A nurse working for 3.5 years in a newborn clinic stated, "Arrival and departure times to camps are big problem. We cannot reach the family while the baby sleeps. They cannot get information about the baby because they cannot go back and forth."

\section{Theme III: Challenges Related to Cultural Differences}

The themes regarding the challenges due to cultural differences are related to nutrition and hygiene.

Subtheme l: Nutrition. Nurses stated that Syrian mothers especially have different nutrition habits and that their perceptions toward breastfeeding are dramatically different. Nurse 9 stated, "....: Syrian mothers think that feeding babies with baby formula is a symbol of wealth. Therefore, they do not want to breastfeed their baby."
Subtheme Il: Hygiene. Nurses stated that mothers' hygiene habits and conditions negatively affected the care services. The statement of nurse II, who was aged 36 years and had worked in the newborn unit for 12 years, about cultural differences is, "Their cleaning habits are quite different. The mothers go to toilet on bare feet and try to breastfeed their babies when they return..." Nurse 13 states that "The mother sits down in a filthy environment, she puts her plate on the floor and eats from it. She says this is clean for her." Stating the effect of hygiene on care, nurse 12 stated, "They come here infested with lice. Nurses wash them with a special shampoo. Giving care to those people is a difficult process for them and for health care personnel."

\section{Theme IV: Effects of Compassion Fatigue on Care}

Subtheme I: Sadness. Nurses stated that their feelings reflect on their emotions when they provide care. Nurses stated that when providing care to the children, they know that these children do not deserve the situation in which they were, which makes them sad.

With a sad facial expression, nurse 12 working in the pediatric infection unit for 17 years made the following statement when she provided care to a Syrian pediatric patient:

The reasons for psychological problems of Syrian children are very different and sad. A mother said that a bomb was dropped on the house of my daughter's uncle when she was there. Since that incident, she has been crying all the time and she does not want doors to be closed. These are the children we care for.

Subtheme II: Empathy. On how they empathize with mothers, nurse 10 stated, "The people we provide care lost their country, do not have home or family, and they have no peaceful place to stay. There are mothers whose relatives were killed in front of their eyes and left them their children;" nurse 3 stated, "These families have changed countries and entrust their children to the person speaking in a different language. From this perspective, it is also a very difficult situation for families. I can understand them, but it hurts me sometimes I feel tired;" and nurse I stated, In my childhood, there was always gunfire. So I can understand 
what they feel. I feel their fears, the happiness of survival. Even the words of love with Syrian mothers are different, when I love her child, firstly she tries to understand what I did and then she smiles. As her we are different in them."

Subtheme III: Feeling of Being Insufficient. The nurses also stated that an increase in the number of general patients and intensive care patients led to an increase in the workload, which in turn made them feel dissatisfied. They stated that infectious diseases negatively affected the maintenance process. A total of 6 nurses working in the newborn intensive care unit expressed their feelings: "...We focus on getting the job done when our workload is too much .... the number of patients we care for everyday is growing incredibly; it is getting harder to provide care; I feel like I cannot provide sufficient care."

\section{Theme V: Recommendations for Decreasing the Challenges}

Subtheme I: Communication. Several solutions could reduce the factors responsible for the difficulties nurses encounter while providing care. These solutions include increasing the number of qualified interpreters in health care, employing Syrian healthcare personnel in the hospital to salvage communication challenges, establishing counseling units, and planning training activities (about the common Arabic words and sentences) for nurses.

Comments from nurse 5 working in the pediatric unit are as follows:

The personnel in counselling unit should have a healthcare background: we are having difficulty in communicating because many interpreters do not have a healthcare background. When we tell the interpreters that the patient's condition is bad, interpreters cannot express the health condition correctly. A mother needed to have MRI scan, but she was told she had to have an operation, thus she started crying. We handled the situation, but what she experienced because of a misunderstanding was unpleasant. For that reason, I think communication should be prioritized.

Subtheme II: Cultural Differences. Nurse 3, who has been working in the pediatric unit for 16 years, expressed her suggestions to overcome the challenges caused by cultural differences:

Information could be provided about how we could approach them .... If we had knowledge of their cultural expectations, our treatment and care could be better. They were strangers to us as much as we were strangers to them. We live in the same way. Information on the characteristics of these patients could be provided within the scope of longer in-service trainings. Employment could be offered to those who could help us.

Subtheme III: Living Conditions. Nurses also made suggestions on how to improve living conditions, increase financial support, and support the use of primary healthcare services.

A nurse working in newborn intensive care unit for 8 years stated the following:

Even though we think that sufficient amount of support is provided, families still suffer. We had to use other families' diapers while waiting for other materials to arrive. The families should be supported financially. Infant diapers for all patients should be available at the hospital without a charge. If patients' problems are eliminated, we could feel comfortable.

Subtheme IV: Workload. Although the nurses stated that providing care to Syrian patients increased their workload in many dimensions, the expectation and recommendations for this problem were much more limited than the suggestions on how to improve patient conditions.

Nurse 4 stated in one sentence that the number of staff could be increased, whereas a pediatric unit nurse 7 made the following recommendation: "The healthcare personnel and the patients need to be systematically and psychologically supported."

\section{DISCUSSION}

This study examined the challenges experienced by the nurses providing care to Syrian pediatric patients and the nurses' recommendations on how to eliminate the challenges. The results of this study are similar to the literature on refugee patients (I0-14), but these results are not comparable because our study was the first to be conducted with nurses working with children who are affected the most by war. The challenges specified by Glenn's study (14) were related to cultural, professional, and individual differences, whereas the subthemes of communication, hygiene, and empathy in the study by Sevinç (10) showed similarity to the subthemes of this study.

Language barrier was one of the factors causing communication challenges. Interpreting assistance to remove this language barrier was not a solution. The use of a common language is the main facilitator of effective communication for the nurses who provide care to traumatic children and parents to learn the patients' history, plan and implement care, and monitor and obtain results. Although the results suggest that the communication challenges can still emerge despite the use of a common language, this study identified the use of different languages along with the fact that the patients were pediatric patients as the major factors causing the difficulty in care. The studies examining the challenges experienced by the patients defined the failure to use a common language as a communication barrier (I5-18). This language barrier in effective care can be overcome by employing bilingual health professionals (19). Therefore, this study highlights interpreters' qualitative insufficiencies in healthcare service as well as quantitative insufficiencies reflecting the limited number of interpreters, and it suggests that a sufficient number of interpreters who are experienced in health care should be employed.

Although Syrians' needs for food, shelter, and health care are provided free of charge by the Disaster and Emergency Management Presidency with the cooperation of the Ministry of Health $(20,21)$, nurses stated that poor living conditions due to economic insufficiency affected the care for the patients. The Syrians living outside the sheltering centers meet their needs in accordance with their economic statutes because the aids for them are more limited than the aids for those living in the centers, which negatively affects the care. Our results are in line with the literature emphasizing that healthcare providers' awareness of the patient's living conditions and requirements in 
this field is significant for the optimization of patient outcomes $(22,23)$.

Cultural diversity is one of the factors that cause difficulty in the implementation of health care. Unlike the literature on nutrition, the biggest difference between Syrian patients and nurses was related to breastfeeding $(24,25)$. Breastfeeding is largely supported in Turkey, whereas Syrian mothers do not like breastfeeding their babies, which causes difficulty for the nurses. Nurses need to be aware of cultural, social, economic, and lifestyle differences that directly affect the health of refugees.

One of the cultural differences is hygiene. Nurses have mentioned the cultural differences in the hygiene practices of Syrian mothers. Nurses said that if the hospital management provided nurses with information about the cultures of Syrian patients, care would be better. They also stated if their living conditions are improved and training in hygiene is planned, their hygiene may be more positively affected. In this way, cultural harmony can be achieved. Thus, the hygiene of Syrian patients is supported. Nurses are waiting for initiatives from the authorities to help them understand Syrian patients' cultural characteristics to overcome these challenges. A study by Almontaser and Bauman (25), who made recommendations for nurses working with Syrian refugees, suggests that hospital management should support nurses in developing cultural sensitiveness and competencies. Although the studies conducted with refugee patients suggested the necessity for nurses' cultural competency, for respect for Syrian patients, and for adopting a nonaccusative attitude toward them, the study by Sagar (15) and Sevinç et al. (10) stated that nurses empathized with mothers and patients despite all challenges (a large number of patients, the increase in the number of patients who need care, and the language barrier and the insufficient number of interpreters).

The empathy and sadness nurses experienced while providing care to the patients were stated. In addition, one of the difficulties experienced by nurses is increased workload because both the burden of care and the number of Syrian patients are very high. The increased workload arising from Syrian patients' practices made nurses feel work centered and dissatisfied. As a result, nurses stated that they felt insufficient. In their study conducted on nurses in the pediatric clinic, Meyer and his colleagues (26) found that compassion fatigue affected job satisfaction. Working with a work-centered mentality and the feeling of insufficiency, sadness, and empathy are among the determinants of compassion fatigue. Although nurses continue to work with empathy and compassion today, empathy and devotion increase the risk of compassion fatigue. It is known that nurses who provide nursing care, constantly observe patients' experience of suffering and fear, and try to understand those experiences are at a greater risk of compassion fatigue. The sample in this study consisted of intensive care nurses and nurses working in pediatric patient care with patients who are exposed to very severe trauma, such as war, which increased the likelihood for those nurses to experience compassion fatigue. Although individual efforts are significant for coping with compassion fatigue, the power of corporate support is indisputable. Nurses in this study stated that they need support. Such managerial initiatives can support nurses working with Syrian patients in dealing with compassion fatigue.
The generalizability of the results is limited because this study was carried out with nurses working in the same institution and with limited numbers. The research results can be generalized to nurses included in the sampling.

Nurses providing care to the children of Syrian refugees suffer from challenges owing to living conditions, cultural differences, compassion fatigue, and particularly, communication-based language barriers. Suggestions for reducing these challenges included improving the number and quality of interpreters; enhancing cultural competence through initiatives, such as planning trainings to cope with cultural differences; and providing support for dealing with compassion fatigue.

Qualitative and quantitative studies with larger sampling to identify the challenges experienced by nurses working with Syrian patients with traumatic patient profiles will increase the comparability of our results. This study is a guide because it is one of the first studies to determine the challenges experienced by nurses providing care to children who constitute the group that is most affected by war. The results of this study can be a guide for making the necessary arrangements such that nurses can provide more effective care while working with patients who have similar characteristics, and these results can aid similar problems that may be experienced in different countries.

Ethics Committee Approval: Ethics committee approval was received for this study from the ethics committee of Harran University Hospital (Approval date: 14.01.2015, No: 2015/4-24).

Informed Consent: Written informed consent was obtained from patients who participated in this study.

Peer-review: Externally peer-reviewed.

Author contributions: Concept - S.T., H.K., C.O., F.E.; Design - H.K., C.O.; Supervision - F.E., C.O., S.T.; Resource - S.T., H.K.; Materials - C.O., H.K.; Data Collection and/or Processing - C.O., H.K.; Analysis and/or Interpretation - S.T., C.O.; Literature Search - S.T., H.K.; Writing - S.T., H.K., F.E.; Critical Reviews - C.O., F.E.

Conflict of Interest: Authors have no conflicts of interest to declare.

Financial Disclosure: The authors declared that this study has received no financial support.

\section{REFERENCES}

I. Mipatrini D, Balcılar B, Dembech M, Ergüder T, Ursu P. Survey on the health status, services utilization and determinants of health of the Syrian refugee population in Turkey. Turkey: WHO Regional Office for Europe Publications: 2019. ). Available from: http://www.euro. who.int/_data/assets/pdf_file/0018/40058I/who-health-survey-report_-25.04.19_with-cover.pdf?ua=I

2. UNICEF. Türkiye'deki suriyeli çocuklar. 2017. Available from: http:// www.unicefturk.org/yazi/acil-durum-turkiyedeki-suriyeli-cocuklar

3. Alpak G, Unal A, Bulbul F, Sagaltici E, Bez Y, Altindag A, et al. Post-traumatic stress disorder among Syrian refugees in Turkey: a cross-sectional study. Int J Psychiatry Clin Pract 2015; 19(I): 45-5. [Crossref]

4. Tahirbegolli B, Cavdar S, C etinkaya Sümer E, Akdeniz S, Vehid S. Outpatient admissions and hospital costs of Syrian refugees in a Turkish university hospital. Saudi Med J 2016; 37(7): 809-12. [Crossref] 
5. Tufan $A E$, Alkin $M$, Bosgelmez $\mathrm{S}$. Post-traumatic stress disorder among asylum seekers and refugees in Istanbul may be predicted by torture and loss due to violence. Nord J Psychiatry 2013; 67(3): 219-24. [Crossref]

6. Gerritsen AA, Bramsen I, Devillé W, van Willigen LH, Hovens JE, van der Ploeg HM. Physical and mental health of Afghan, Iranian and Somali asylum seekers and refugees living in the Netherlands. Soc Psychiatry Psychiatr Epidemiol 2006; 4I(I): 18-26. [Crossref]

7. Al-Rousan T, Schwabkey Z, Jirmanus L, Nelson BD. Health needs and priorities of Syrian refugees in camps and urban settings in Jordan: perspectives of refugees and health care providers. East Mediterr Health J 2018; 24(3): 243-53. [Crossref]

8. Sevinç S, Kılıç SP, Ajghif M, Öztürk MH, Karadağ E. Difficulties encountered by hospitalized Syrian refugees and their expectations from nurses. Int Nurs Rev 2016; 63(3): 406-14. [Crossref]

9. Sevinç S, Ajghif M, Uzun Ö, Gülbil U. Expectations of relatives of Syrian patients in intensive care units in a state hospital in Turkey. $J$ Clin Nurs 2016; 25(I5-16): 2232-4l. [Crossref]

10. Sevinç, S. Nurses' Experiences in a Turkish internal medicine clinic with Syrian refugees, J Transcult Nurs 2017; 29(3): 258-64. [Crossref]

II. Türkiye İstatistik Kurumu, Available from: http://www.tuik.gov.tr/ Start.do;jsessionid=XmTCbjhDXvV7Qv4MSpshr0Tv7pYtx7RthhPbyrz†5vJ5IMmZysqv!-1001318833

12. Yıldırım A, Șimșek H. Sosyal bilimlerde nitel araștirma yöntemleri (Qualitative research methods in social sciences). Seçkin Yayıncllık. 20II. Ankara, Turkey.

13. Clarke $\vee$, Braun $\vee$. Teaching thematic analysis: Overcoming challenges and developing strategies for effective learning. Psychologist. 2013; 26: 120-3.

14. Glenn F. Culture and the patient-physician relationship: Achieving cultural competency in health care. J Pediatr 2000; 136: 14-23. [Crossref]

15. Sagar PL. Transcultural nursing theory and models application in nursing education, practice and administration. New York, NY: Springer. 2012
16. Adams AMN, Mannix T, Harrington A. Nurses' communication with families in the intensive care unit - a literature review. Nurs Crit Care 20l5; 22(2): 70-80. [Crossref]

17. Arnold RM, Back AL, Barnato AE, Prendergast TJ, Emlet LL, Karpov l, et al. The critical care communication project: improving fellows' communication skills. J Crit Care 2015; 30(2): 250-4. [Crossref]

18. Hudelson P, Vilpert S. Overcoming language barriers with foreign-language speaking patients: a survey to investigate intra-hospital variation in attitudes and practices. BMC Health Serv Res 2009; 9: I-9. [Crossref]

19. McNeely, CA, Morland L. The health of the newest Americans: How US public health systems can support Syrian refugees. Am J Public Health. 2016; 106(I): 13-5. [Crossref]

20. Afet ve Acil Durum Yönetimi Bașkanlığı. Suriyeli sığınmacılara yapılan yardımlar. 2017. Available from: https://www.afad.gov.tr/ afet-raporu---suriye

21. İçișleri Bakanlığı Göç İdaresi Genel Müdürlüğü Yayınları, 2017 Yayın No: 40, Available from: http://www.goc.gov.tr/icerik3/turkiye\%E2\%80\%99de-gecici-koruma_409_558_1097.

22. Napier AD, Ancarno C, Butler B, Calabrese J, Chater A, Chatterjee $\mathrm{H}$. et al. Culture and health. Lancet 2014; 384: 1607-39. [Crossref]

23. Doocy S, Lyles E, Akhu-Zaheya L, Burton A, Burnham G. Health service access and utilization among Syrian refugees in Jordan. Int J Equity Health 2016; 15(I): 108. [Crossref]

24. Padela Al, Gunter K, Killawi A, Heisler M. Religious values and healthcare accommodations: Voices from the American Muslim community. J Gen Intern Med 2012; 27(6): 708-15. [Crossref]

25. Almontaser $E$, Baumann SL. The Syrian refugee crisis: what nurses need to know, Nurs Sci Q 2017; 30(2): 168-73. [Crossref]

26. Meyer RM, Li, A, Klaristenfeld J, Gold Jl. Pediatric novice nurses: examining compassion fatigue as a mediator between stress exposure and compassion satisfaction, burnout, and job satisfaction. J Pediatr Nurs 2015; 30(I): 174-83. [Crossref] 